viduals who compose the mass, each one being represented by a dot. His diagram, adapted in $(a)$ of the present figure, stands for a population descended from a common ancestral stock, the individuals congregating most closely about the place of the central type or standard individual, and gradually decreasing in numbers as they become more different from that type or standard. In this graphic representation, the race can, of course, only be arranged in order as to some one quality. In the particular case for which Mr. Galton uses it, this quality is stature. The individuals of the mean or average height (say, 5 ft. 8 in.) are shown as most crowded, while the taller and shorter men become fewer and fewer as their stature becomes more unusual, till at last we come to one or two outlying giants and dwarfs, beyond whom no more individuals exist. Here, then, is set before us the distinctest idea of a race, both as to its type and as to its limits of variation on either side. I now proceed to apply the method of this diagram to a more complex state of things.

In nature we habitually find races blending into one another. Our own species shows this perfectly, when mixed breeds are considered. Let a population partly of Europeans and partly of negroes be placed on a West Indian island. These two races being classified according to colour, a few of the darkest Europeans would be seen to make some slight approach towards a few of the lightest negroes; but there would be no individual of either race who could be mistaken for one of the other. They would, therefore, at the outset be represented by two such groups of dots as ( $(n)$, with a blank space between. But as soon as the first generation of mulattos come into existence the case will be altered. An intermcdiate race has arisen with its definite central type, and its variants now coming much closer to the whites on one side and to the blacks on the other. In the next generation there will be quadroons and sambos (cross between negro and mulatto, Spanish z(ambo). Now the fusion will be so complete, that of many individuals it will hardly be possible to say whether they are quadroon or mulatto, while in the same way others may be either mulatto or sambo, or either sambo or negro. One or two more generations would still further obliterate the distinction between a jjoining varieties, but for convenience sake the figure (b), showing the blended races, is taken only in the second generation. In this way the whole human species, or any species of plants or animals, may be ideally classified into its various races, either in fact blending into one another, or capable of so blending by intercrossing. A species thus classified into its component races is shown either in $(b)$ or the central part of $(c)$.

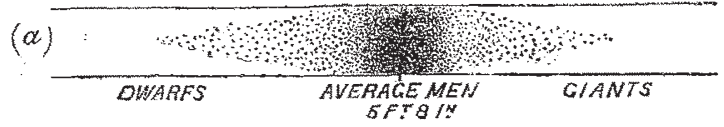

(b)

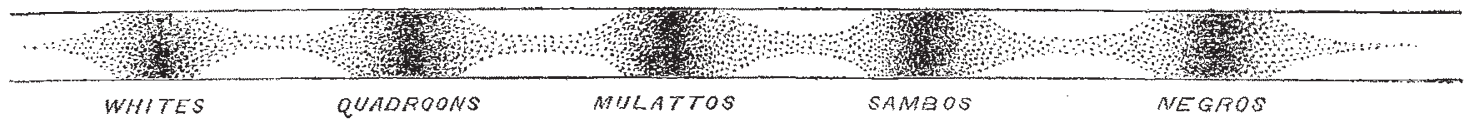

(c)

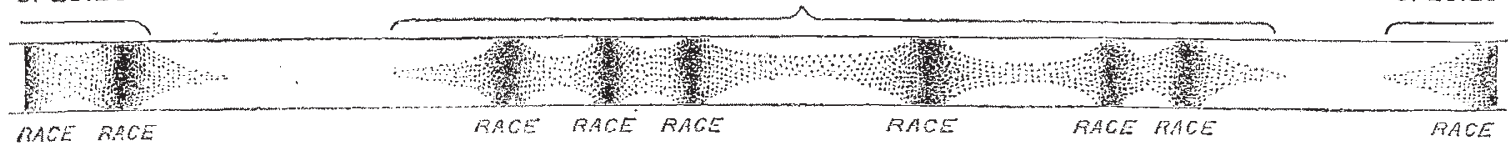

Let us now attend to the effect of variation, artificial or natural. Starting with a single race, this may in the course of time and circumstance develope within itself a number of varieties or races. Nor, if variation is promoted either under domestication or by various conditions of life acting for a long series of generations, is there any difficulty in conceiving two adjacent varieties to recede from one another and the intermediate individuals to die out, till a wide gap is left between the two races. At first this gap, though real, would be capable of being at any time bridged over by cross-breeding, and thus would only be a temporary break. But as variation went on, a critical period would at last be reached, when individuals from the tivo sides could no longer produce fertile offspring. Then a separation of one species into two would have taken place. This change is illustrated in $(c)$, where the extreme forms of two adjacent species are seen to the right and left, still perceptibly near the extremes of the original species from which they have parted, but never to be joined to it again unless by a process of backward variation most unlikely to happen across any width of interval. This ideal representation was at first intended rather to show the actual distribution of animals in existing species than to involve a hypothesis as to how these species originated. But, after consulting Mr. T. R. Stebbing, I see the desirableness of making the diagram express both facts and hypothesis, leaving those who will to take them apart. The wholo foure, as it stands, contains an ideal of evolution or development from a single race of animals at $(a)$, into a species made up of several races at $(b)$, and thence into any number of separate species at $(c)$.

EDVARD B. TYLOR

\section{TRANSIT OF VENUS}

Colonel Tennant's Station at Roorke, Indiu.

THE full and very able account of the preparations for observing the Transit of Venus drawn up by Prof. Forbes and published in these columns do not include those which have been made by the Government of India under the authority of the Secretary of State in Council. When Prof, Forbes wrote, these were not sufficiently advanced to admit of description. Now that they are completed it is desirable that an account of them should be made public.

At an early period Col. J. F. Tennant, R.E., F.R.S., brought the subject before the Viceroy in India, and proposed the organisation of a station in the north-west near Roorkee, well known as the seat of the great Civil Engineering College. The Viceroy heartily responded to the suggestion, and communicated his views to the Home Government.

Some time was unfortunatyly lost in offecil currespond. 
ence, and it was not until July 1873 that I received final authority to order the necessary instruments. With the sanction of the Secretary of State, I conferred with Mr. Warren De la Rue on the subject, and am indebted to that gentleman's zeal and experience for a great deal of valuable assistance.

The following is a list of instruments prepared by $\mathrm{Mr}$. De la Rue and myself, and sanctioned by Government :I Photoheliograph.

I Equatoreal.

I Altazimuth.

I Transit Instrument.

1 Chronograph.

I Standard Clock.

3 Journeyman Clocks.

I will briefly describe each of these.

Photoheliograph.-This is of the same identical size and construction as those supplied to the stations equipped under the auspices of the Astronomer Royal. It is well known that these have been constructed from the designs of Mr. De la Rue and under his close personal supervision. I therefore advised that that gentleman, as the first authority on the subject, should be requested to superintend the provision of this particular instrument, and that he should have carte blanche for the introduction of any improvements or additions suggested by his constantly enlarging experience. My recommendation was adopted, and I need hardly say that Mr. De la Rue, with his usual public spirit, at once gave his services to the Government and to science. This instrument, like its prototypes, was made by $\mathrm{Mr}$. Dallmeyer. Janssen's apparatus, modified by Mr. De la Rue, for multiplying the photograms, has been supplied to this instrument.

Equatoreal.-This has an object-glass of six inches clear aperture. It was made by Messrs. Cooke and Sons, of York, and is generally of the form which those artists have made familiar to the astronomical world. It is a universal instrument, being capable of adjustment for any latitude to $67^{\circ} 39^{\prime}$, and in either hemisphere, for which latter purpose it has reversible driving-gear and two hourcircles readily interchangeable. Besides a siriding level for making the declination axis horizontal, two delicate levels are suspended from the centre of the telescope. A graduated circle and delicate level is also attached to the telescope near its cyc end. This, in conjunction with a micrometer in the eye-piece, will qualify the instrument for determining latitude by the differential observation of two stars of nearly equal zenith distances, north and south. The instrument has two micrometers-a parallel wire by the makers, and a double image micrometer by Messrs. Troughton and Simms, precisely similar to those supplied for other stations under the auspices of the Astronomer Royal. The parallel wire micrometer has a contrivance intended to enable the observer to record the readings of the divided head without withdrawing his eye from the eye-piece, as suggested by Mr. Christie, of the Royal Observatory. The form actually adopted by the makers differs both from that employed by Mr. Christie and that prescribed by me. I am unable to express any opinion on its efficiency, as it arrived from the makers aiter the instrument had been despatched to India, and I could not try it.

The instrument is well supplied with eye-pieces and all necessary adjuncts, and the arrangements for bringing down the various adjusting and slow-motion screws to the observer's hand when observing are very complete, and many of them, I believe, as novel as they are ingenious and effective.

I had but one brief opportunity of trying the objectglass, but that sufficed to satisfy me that it is of a high order of excellence.

Altazimuth. - The place of this is supplicd by the great theodolite constructed, from my designs, by Messrs.
Troughton and Simms, for the Great Trigonometrical Survey of India, and now about to be employed for the first time. The main features of this instrument were described by me in a paper read before the Royal Society and published in its Proceedings, No. 135, of 1872. I may briefly state here that the horizontal circle is three feet in diameter, read by five equidistant micrometers, the circle being fixed and the micrometers revolving; that the vertical circle is two feet in diameter, read by either two micrometers fixed, or by four capable of being shifted so "as to change the divisions and thus reduce errors of graduation; and that the telescope has an aperture of 3.25 in., and a focal length of 36 in., to which can be attached either of two parallel wire micrometers-one for measuring in the vertical, the other in the horizontal plane, according to the class of observation, the wires having both a dark and a bright field illumination.

This is no doubt the most elaborate and most powerful instrument of its class in existence.

Transit Instrument.-This is of a peculiar and, I believe, in many respects novel form. It is from the designs of Signor Magnaghi, of Genoa, modified by the makers, Messrs. Cooke, of York, and myself. Signor Magnaghi's object was to produce an instrument capable of determining latitude, as well as of performing the usual functions of a transit instrument, those of determining time and longitude. The telescope has an aperture of 3 in. and a focal length of $34 \frac{7}{8}$ in. with a transit axis of the usual form 181 in, in length between the pivot shoulders. The stand is of cast iron, and consists of first a massive circular base plate 24. in. in diameter, supported, according to the system introduced by me, by three shakeless foot-screws, upon a single masonry pillar. On the base plate revolves horizontally a second similar plate with the two pillars cast hollow in one piece with it. This upper revolving plate moves stiffly, and is provided with slow-motion screws and four powerful clamping bolts. When it is bolted to the lower base plate, the two may be considered practically to be one mass. The horizontal motion thus provided is used, first, for effecting the ordinary azimuthal adjustment of the instrument to the plane of the meridian; and secondly, the direction of the meridian having been found, for placing the telescope with great facility in the plane of the prime vertical for the determination of latitude by that method.

An apparatus is also supplied for lifting the telescope and reversing its pivots on their bearings, the transit axis level remaining suspended from the pivots during the process. This arrangement also admits of the instrument being used to determine latitude by the differential observation of two stars of nearly equal zenith distances, north and south ; for which purpose the telescope is provided with a parallel wire micrometer and a delicate level.

Chronograph,-Col. Tennant attached, justly I think, great importance to means being provided for the electric record of the time observations which form so essential a portion of the undertaking. He wished to have a chronograph which should be capable of recording at the same time, and without confusion, observations made with four different instruments, viz., the Photoheliograph, Equatoreal, Altazimuth, and Transit Instrument, and he indicated the apparatus described by Lord Lindsay in Monthly Notices, R.A.S. I therefore examined Lord Lindsay's chronograph, then under construction by Messrs. Cooke, of York, but, though no doubt suitable for a fixed observatory, such as his lordship is establishing, I thought it too large and ponderous for the present service. I accordingly arranged with Messrs. Cooke a much lighter and, I may add, a less costly plan. By substituting continuous bands of paper, similar to those used in telegraphic instruments, for sheets of paper carried by the large barrels employed by Lord Lindsay, great increase of compactness and lightness were secured. Four such bands are 
worked by one central clock movement, each or all being readily thrown out of gear at will. The marking is cffected by steel prickets driven by electro-magnets, on the same principle as in the chronograph of the Royal Obscrvatory, Greenwich, though the mechanical details were different. These prickers can also be thrown out of action by a convenient arangement of resistance coils. 'The icngth of a single second of time can, by changing two whecls, be made either on e, three-quarters, or half an inch. I had prescribed that the central clock work should be regultited citber by the late Lcon Foucault's lever governor or by Mr. Siemens' centrifugal fuid governor, but the maker, without consulting me, applied a Watts ball rovemor with friction-brake, such as is employed for the driving-clock of equatoreals. I dicl not expect that this comparatively primitive contrivance would secure a sufficiently uniform velocity. But on trial by Capt. Campoell, R.E., and myself, it was found to answer its purpose so well that $I$ am inclincd to think a great deal of needless refinement and expense has bcen wasted on elaborate rovernors for chronographs.

Standard Clock. - This is by Messis. Cooke, of York, and has nothing pecular in its construction. It has a Graham's dead beat escapement, and a mercurial (metal jar) compensated pendulum, with the contact apparatus necessary for connecting it electrically with the chronograph.

Thre Founcyman Clocks.-.'These were intended by me to be connected electrically with the Standard Clock, and thus show identical time for each of the principal instruments from which the latter might not be visible. I was not satisficd with the mode of driving adopted by the makers, and should have had them altered if time had admitted. Col. Tennant is also dissatisfied with them, but I hope that, with careful adjustment and attention to the batteries and contacts, they may be found effective during the short period of the phenomenon.

It fortunately happened that whilst these instruments were undergoing examination by me, Capt. W. A. Campbell, R.E., of the G. T. Survey of India, who is to assist Col. Tennant with the Venus observations, was in England. The Government, on my application, appointed Capt. Campbell to assist me in testing the instruments, and thus the two objects vere gained of securing his valuable cxpericnce and skill, and of familiarising him with the instruments which he would have to use.

I have heard from Col. Temant of the safe arrival at kookce of the photoleliorraph, altazimuth, chromorraph, and clocis, and of the expected arrval in a few days of the Equatoreal, his last letter to me to that effect being dated gth Oct., 1874 . There would only remain the Transit Instrument, which was much delayed in construction. It was despatched hence on Sept. 18, 1874, and is no doubt now in Col. Tennant's lands.

In the foregoing statement $I$ have confined myself to those arrangements which I have been personally concened in making. But other places in India will be provided with equipments more or less complete for observing the Transit of Venus-amongst others I may mention l'eshawur, bombay, and probably more than one station in the southern part of the peninsula under the care of Mr. Pogson, Government Astronomer at Madras. The Government of India has thus not been unmindful of the just claims of astronomical science.

A. STRANGE, Lieut.-Colonel, Inspector of Scientific Instruments Lanbeth Ubservatory, Nov. 1874

to the Government of India

IRACTICAL SCIENCE AT CAMBRIDGE

I) MICHAEL FOSTER, in concluding his course of Practical Physiology this term, remarked on the diligence and industry of his class under many difficulties.
At the beginning of the term he asked their indulgence for the imperfect accommodation he was able to offer them. Thirty students had been entered, and the space available was about sufficient, properly, for ten. Three students had to be placed at each table, instead of one. Several other gentlemen joined the class subsequently, making the class number about thirty-five. Two ladies also attended the lectures, and were provided with a separate place of study. Dr. Foster at his last lecture said that in the previous year the want of accommodation had been so keenly felt by himself and class that he was inclined to discontinuc his course. He had, however, conducted it through another term, with a larger number of students; and, as the result, although he expressed pleasure at the work accomplished by his class, he was more than ever inclined to give it up. The present course would, however, be completed next term ; but he was not able to promise its repetition in the succeeding winter. Want of accommodation militated so greatly against the quality of the work done, and so limited the kind of work that could be attempted, that the benefit seemed almost to be outweighed by the limitations and disheartening accessories.

The publication of these remarks may serve to draw attention to the general condition of practical science in Cambridge. Chemistry and geology are perhaps the subjects for the practical study of which we now have the most reasonable facilities. The Chemical Laboratory has been recently enlarged and improved, and in addition to the ordinary practical courses Prof. Liveing has this term given lectures with practical illustrations in spectroscopic analysis. The lectures have been given during four successive hours of the afternoon, to four sets of students, the number of students in each class being limited to four or five; so that thoroughly efficient work could be done. The facilities for study at the Geological Museum have been improved by Prof. Hughes. A typical collection of fossils has been selected and arranged by Mr. Keeping, and provided with catalogues. A typical series of minerals has been arranged and catalogued by Mr. W. E. Koch, B.A., of St. John's College, derived from the ample stores accumulated by the late Prof. Sedgwick. Several large series of rock specimens have been more conveniently arranged for inspection, including those catalogued by the Rev. T. G. Bonney. In addition, advanced students have free access to the many valuable special collections in the Woodwardian Musenm. The Geological Library iit the nuscum has been improved and catalogued; a valuable section-cutter and an excellent microscope have been purchased, and in other ways the means for the practical study of geology, so far as it can be carried on in a museum, have been greatly improved.

In Experimental Physics the best conditions for practical study have been secured in the building of the Cavendish Laboratory, in its being furnished with some of the most perfect and valuable physical apparatus in existence, and in the appointment of Prof, Clerk Maxwell and his able demonstrator, Mr. Garnett. No doubt at the earliest possible moment a practical elementary course will be organised, to include those observations which every student of natural science should become familiar with. Sufficient time has not yet elapsed since the completion of the laboratory for the establishment of such an elcmentary class; but winen it is established a great boon will be conferred on Natural Science students, who, in the study of biology and geology, labour under many difficulties caused by a want of sufficient practical acquaintance with physics. It would be very desirable, also, if some elementary non-mathematical lectures on physics could be given for the benefit of Natural Science students; such lectures might be given by the Demonstrator, so as not to interfere unduly with Prof. Maxwell's researches and advanced mathematical lectures. It is true that $\mathrm{Mr}$. Trotter gives valuable lectures on physics 